Published in final edited form as:

Sci Transl Med. 2018 May 02; 10(439): . doi:10.1126/scitranslmed.aao4521.

\title{
TLR7 agonists induce transient viremia and reduce the viral reservoir in SIV-infected rhesus macaques on antiretroviral therapy
}

\author{
So-Yon Lim ${ }^{1}$, Christa E. Osuna ${ }^{1}$, Peter T. Hraber ${ }^{2}$, Joe Hesselgesser ${ }^{3}$, Jeffrey M. Gerold ${ }^{4}$, \\ Tiffany L. Barnes ${ }^{3}$, Srisowmya Sanisetty ${ }^{1}$, Michael S. Seaman ${ }^{1}$, Mark G. Lewis ${ }^{5}$, Romas \\ Geleziunas $^{3}$, Michael D. Miller ${ }^{3}$, Tomas Cihlar ${ }^{3}$, William A. Lee ${ }^{3}$, Alison L. Hill ${ }^{4}$, and James \\ B. Whitney ${ }^{1,6, *}$ \\ ${ }^{1}$ Center for Virology and Vaccine Research, Beth Israel Deaconess Medical Center, Harvard \\ Medical School, Boston, MA 02215, USA \\ ${ }^{2}$ Los Alamos National Laboratory, Los Alamos, NM 87545, USA \\ ${ }^{3}$ Gilead Sciences Inc., Foster City, CA 94404, USA \\ ${ }^{4}$ Program for Evolutionary Dynamics, Harvard University, Cambridge, MA 02138, USA \\ ${ }^{5}$ Bioqual, Rockville, MD 20852, USA \\ ${ }^{6}$ Ragon Institute of Massachusetts General Hospital, Massachusetts Institute of Technology, and \\ Harvard, Cambridge, MA 02139, USA
}

\begin{abstract}
Antiretroviral therapy (ART) can halt HIV-1 replication but fails to target the long-lived latent viral reservoir. Several pharmacological compounds have been evaluated for their ability to reverse HIV-1 latency, but none has demonstrably reduced the latent HIV-1 reservoir or affected viral rebound after the interruption of ART. We evaluated orally administered selective Toll-like receptor 7 (TLR7) agonists GS-986 and GS-9620 for their ability to induce transient viremia in rhesus macaques infected with simian immunodeficiency virus (SIV) and treated with suppressive ART. In an initial dose-escalation study, and a subsequent dose-optimization study, we found that TLR7 agonists activated multiple innate and adaptive immune cell populations in addition to inducing expression of SIV RNA. We also observed TLR7 agonist-induced reductions in SIV DNA and measured inducible virus from treated animals in ex vivo cell cultures. In a second study, after stopping ART, two of nine treated animals remained aviremic for more than 2 years,
\end{abstract}

\footnotetext{
*Corresponding author. jwhitne2@bidmc.harvard.edu.

Author contributions: J.H., T.C., M.D.M., R.G., W.A.L., and J.B.W. designed the studies. S.S., C.E.O., M.S.S., and S.-Y.L. did the virological assays and viral sequencing. S.S., S.-Y.L., and C.E.O. did the immunological assays. J.H., T.L.B., and S.-Y.L. performed the cytokine and chemokine analysis. P.T.H. did the bioinformatics analysis. A.L.H. and J.M.G. did the mathematical modeling. J.B.W. and M.G.L. performed the interventions and clinical care of the rhesus monkeys. J.B.W. led the studies and wrote the paper with all co-authors.

Competing interests: J.H., R.G., T.C., M.D.M., and W.A.L. are employees of Gilead Sciences and own stock and/or stock options of Gilead Sciences. R.G. and J.H. are co-inventors on patent application \#2016/007765 filed by Gilead Sciences Inc. that covers the use of TLR7 modulators for treating HIV infections. TLR7 modulators are available from Gilead Sciences Inc. under a material transfer agreement. The other authors declare that they have no competing interests.
} 
even after in vivo $\mathrm{CD} 8^{+} \mathrm{T}$ cell depletion. Moreover, adoptive transfer of cells from aviremic animals could not induce de novo infection in naïve recipient macaques. These findings suggest that TLR7 agonists may facilitate reduction of the viral reservoir in a subset of SIV-infected rhesus macaques.

\section{INTRODUCTION}

The HIV-1 latent reservoir persists despite long-term antiretroviral therapy (ART) $(1,2)$, necessitating the development of new strategies for viral eradication $(3,4)$. Latency reversal agents (LRAs) have been evaluated as a potential means to reduce the HIV-1 reservoir $(4,5)$. Early clinical studies of LRAs have provided evidence of modest HIV-1 activation (6-9) but have failed to reduce the viral reservoir (9-14). First-generation LRAs, such as histone deacetylase (HDAC) inhibitors, may also harbor immunosuppressive properties that may not be compatible in combination with some immune-enhancing therapeutic strategies aimed at HIV-1 eradication $(15,16)$. Collectively, these studies underscore the need for the continued development of new, safe, and efficacious LRAs.

Here, we sought to evaluate potent, selective, and orally delivered small-molecule agonists of Toll-like receptor 7 (TLR7) that induce potent immune responses and thus may affect the HIV-1 reservoir. Vesatolimod (GS-9620) is a TLR7 agonist that has demonstrated antiviral activity in animal models of hepatitis B virus and has already progressed to advanced clinical testing (17-19). The GS-9620 analog GS-986 has been used as an investigational tool compound and has a similar pharmacological profile to GS-9620.

\section{RESULTS}

To assess the therapeutic potential of TLR7 agonists in vivo, we selected 21 Indian-origin rhesus macaques that did not express the major histocompatibility complex (MHC) class I alleles Mamu- $A^{*} 01$, Mamu- $B^{*} 08$, or $M a m u-B^{*} 17$, which are associated with enhanced control of simian immunodeficiency virus (SIV) replication (20). All rhesus macaques were infected intrarectally with the SIVmac251 isolate using a repeated low-dose mucosal challenge protocol as described (21). Once infection was confirmed, all animals began a highly potent ART regimen of tenofovir (TFV), emtricitabine (FTC), and dolutegravir (DTG) as a daily subcutaneous injection at day 65 after infection, as described (22). Plasma SIV RNA was assessed longitudinally throughout the study. On ART, plasma SIV RNA in all rhesus macaques declined rapidly and remained undetectable (SIV RNA at $<50 \mathrm{copies} / \mathrm{ml}$ of blood; fig. S1A). After about 400 days of ART suppression, animals were divided into two study cohorts and then into separate treatment and control arms for each study (fig. S2).

At study assignment, before the initiation of TLR7 agonist dosing, there were no significant differences in the area under the curve (AUC) viral burden (range, log 8.0 to 9.3), median plasma SIV pre-ART (range, $\log 4.5$ to $6.6 \mathrm{RNA}$ copies $/ \mathrm{ml}$ ), time to viral suppression (range, 14 to 103 days), or $\mathrm{CD}^{+}$and $\mathrm{CD} 8^{+} \mathrm{T}$ cell numbers $\left(\mathrm{CD} 4^{+} \mathrm{T}\right.$ cells per microliter of blood, 256 to 1486 versus 557 to 1316; CD8 ${ }^{+} \mathrm{T}$ cells per microliter of blood, 552 to 1048 versus 309 to 1283, respectively) between groups (fig. S1B). 
Our first study (Study 1) used 10 SIV-infected rhesus macaques that had been on ART for more than 437 days before TLR7 agonist dosing. GS-986 was dose-escalated in 4 of 10 macaques with administration every other week by oral gavage, whereas the remaining 6 macaques served as controls. The initial dose of GS-986 was $0.1 \mathrm{mg} / \mathrm{kg}$ followed by a dose at $0.2 \mathrm{mg} / \mathrm{kg}$ and then five doses at $0.3 \mathrm{mg} / \mathrm{kg}$ (fig. S2A).

We longitudinally monitored several immunologic and virologic parameters before, during, and after GS-986 dosing. The activation of major lymphocyte subsets in the peripheral blood after each dose of GS-986 was measured by surface expression of CD69. All cell types evaluated $\left[\mathrm{CD} 4^{+} \mathrm{T}\right.$ cells, $\mathrm{CD} 8^{+} \mathrm{T}$ cells, B cells, and natural killer (NK) cells] were transiently activated within 24 to 48 hours after GS-986 treatment and returned to baseline before the next dose (Fig. 1A). However, $\mathrm{CD} 8^{+} \mathrm{T}$ cells and $\mathrm{NK}$ cells showed the greatest change in percentage activation after GS-986 administration. With the exception of B cells, cellular activation was dose-dependent and plateaued during repeated dosing at $0.3 \mathrm{mg} / \mathrm{kg}$ (doses 4 to 7). The percentage of $\mathrm{CD}^{+}{ }^{+} \mathrm{T}$ cells that were activated after GS-986 treatment was 1 to $2 \%$ of the population, whereas 20 to $25 \%$ of NK cells and $\mathrm{CD}^{+} \mathrm{T}$ cells became activated after GS-986 treatment. As expected, for the selected GS-986 doses, plasma interferon- $a$ (IFN- $a$ ) was detected after GS-986 administration and was dose-dependent (fig. S3A).

We next assessed the impact of GS-986 dosing on plasma viremia in rhesus macaques on suppressive ART. The first three doses of GS-986 administered to the four SIV-infected ART-suppressed macaques had no effect on plasma viremia. However, further administration induced transient SIV plasma RNA in all macaques (Fig. 1B). We detected plasma SIV RNA blips in two animals after the fourth dose, and during doses 5 to 7 , all rhesus macaques displayed a moderate level of transient viremia (500 to 1000 SIV RNA copies/ml). Plasma viremia peaked 24 to 48 hours after GS-986 exposure and returned to baseline suppression ( $<50$ SIV RNA copies/ml) within 4 to 7 days after GS-986 dosing (Fig. 1B). All vehicletreated control rhesus macaques remained aviremic throughout the study.

To assess the nature of the SIV plasma blips elicited by GS-986, we performed singlegenome sequencing of viral RNA isolated from the blood plasma (during blips) and proviral DNA from peripheral blood mononuclear cells (PBMCs), gastrointestinal mucosa mononuclear cells (GMMCs), and lymph node mononuclear cells (LNMCs), as described (23). The sequence of SIV group-specific antigen (gag) and SIV envelope (env) coding regions isolated during the GS-986-induced plasma blips shared phylogenetic identity to the low-diversity, monophyletic sequences prevailing in PBMCs, GMMCs, and LNMCs, suggesting that the released virus arose from a reservoir pool established very early after infection (fig. S4A). Moreover, some of the proviral sequences analyzed from blood and tissues isolated from treated and control animals were found to be more diverse than the plasma blip sequences. These proviral sequences were generally phylogenetically distinct from the GS-986-induced plasma viral RNA sequences. Specifically, SIV DNA sequences were found to harbor hypermutated defective proviral sequences, implying that the GS-986induced SIV RNA possibly arose from replication-competent provirus (fig. S4, A and B). 
To determine whether the env genes of the GS-986-induced plasma viruses were infectious, we produced SIV pseudovirion stocks encoding all 11 full-length env sequences cloned from GS-986-induced plasma virus blips $(n=4)$ and from env sequences isolated from cellassociated proviral DNA $(n=7)$. We then generated SIV-env pseudoviruses that were evaluated using a $T Z M-b l$-based infectivity assay. We found that three of four plasma virus blip-derived SIV env constructs were infectious at levels comparable to wildtype SIVmac251 env. Only one env gene cloned from the plasma virus blip RNA was noninfectious. All seven env sequences cloned from proviral DNA were markedly hypermutated and thus failed to mediate infection in this assay (fig. S5).

To further assess the impact of the GS-986 regimen on the viral reservoir, we evaluated SIV DNA in sorted $\mathrm{CD}^{+}{ }^{+} \mathrm{T}$ cell populations isolated from PBMC, GMMC, and LNMC samples before the first exposure (pre-TLR7) and 1 week after the last dose of GS-986 (post-TLR7). Specifically, $\mathrm{CD}^{+} \mathrm{T}$ cell subpopulations were sorted into naïve $\left(\mathrm{T}_{\mathrm{N}}\right)$, central memory $\left(\mathrm{T}_{\mathrm{CM}}\right)$, transitional memory $\left(\mathrm{T}_{\mathrm{TM}}\right)$, and effector memory $\left(\mathrm{T}_{\mathrm{EM}}\right) \mathrm{T}$ cells. The $\mathrm{T}$ cell memory populations were then pooled for SIV DNA measurements. In GS-986-treated rhesus macaques, an average reduction of $75 \%$ was observed in SIV DNA (Fig. 2). SIV DNA remained largely unchanged in the vehicle-treated control rhesus macaques. SIV DNA in the $\mathrm{CD}^{+}$memory $\mathrm{T}$ cell populations had declined in LNMCs from all four GS-986-treated rhesus macaques and from three of four macaques in PBMCs. GS-986 treatment reduced SIV DNA in the GMMC-derived CD4 ${ }^{+} \mathrm{T}$ cells in all four treated animals to undetectable levels (fig. S6).

Two weeks after the final GS-986 dose, ART was discontinued to determine whether GS-986-associated plasma viral blips and reduction in viral DNA would alter SIV rebound kinetics. Rebound viremia occurred in all animals within 7 to 10 days after stopping ART (Fig. 3). We analyzed the kinetics of SIV RNA rebound in the plasma from all 10 rhesus macaques through day 84 after stopping ART but did not observe any difference in the time to SIV rebound between GS-986- or vehicle-treated control animals (Fig. 3). We next assessed viral peak (weeks 2 to 3), set point (weeks 7 to 8), and total viral burden for each macaque by calculating the AUC of SIV RNA between days 1 and 56 after ART cessation. Analyses of all three parameters showed reduced plasma SIV RNA in GS-986-treated animals relative to those of controls; however, the differences were not significant (peak, $P=$ 0.476; set point, $P=0.171$; and AUC, $P=0.476$; fig. S7A). We then repeated all statistical tests without the single control animal with unusually low viremia. The differences in both viral peak and AUC between treated and control rhesus macaques reached statistical significance ( $P=0.008$ and $P=0.02$, respectively). The same statistical tests were also conducted, adding nine additional historic control animals that received the same SIV stock, dose, and route, and had also initiated ART at day 65 after infection (fig. S7B). Viral kinetics after ART cessation in these additional control rhesus macaques did not show a difference in rebound compared to five of the six control animals from study 1 . Viral peak and set point analyses found a significant median reduction of SIV RNA in GS-986-treated rhesus macaques compared to controls ( $P=0.03$ and $P=0.04$, respectively). The difference in AUC between treated and control rhesus macaques also was statistically significant ( $P=0.01$; fig. S7C). This reduction in median set point viremia in GS-986-treated rhesus macaques persisted for the entire 84-day monitoring period after ART cessation. 
In study 2, we compared the drug analog GS-986 to the clinical TLR7 agonist molecule GS-9620 for the ability to induce transient viremia and reduce the SIV reservoir. We also evaluated two clinically relevant translational end points. The first end point was to determine whether dose reductions were effective in limiting peripheral IFN- $a$ that, if too high, often results in clinical participants experiencing "flu-like" symptoms. The second end point was to assess the tolerability and efficacy of an increased number of TLR7 agonist doses. Eleven SIV-infected ART-suppressed rhesus macaques were divided into four groups based on viral load pre-ART, time to viral suppression after ART initiation, and CD4 ${ }^{+}$, $\mathrm{CD}^{+}$, and $\mathrm{CD}^{+} / \mathrm{CD}^{+} \mathrm{T}$ cell ratios (fig. S1B). Group 1 served as placebo controls $(n=2)$ and received formulation vehicle only. Group $2(n=3)$ received GS-986 $(0.1 \mathrm{mg} / \mathrm{kg})$, and groups 3 and 4 ( $n=3$ per group) received lower $(0.05 \mathrm{mg} / \mathrm{kg}$ ) or moderate $(0.15 \mathrm{mg} / \mathrm{kg})$ doses of GS-9620 (fig. S2B). All animals received 10 doses of either GS-986 or GS-9620 every other week, followed by a rest period of 3 months while maintained on ART. After the treatment pause, we resumed dosing in all groups (with the exception of group 4) for an additional nine doses at the same dose concentration and frequency.

We monitored the same virologic and immunologic end points as in study 1 . In study 2 , the reduced doses of GS-986 and GS-9620 had similar effects in regard to the activation of NK, $\mathrm{T}$, and B cells. However, we observed that GS-986 at the doses of $0.1 \mathrm{mg} / \mathrm{kg}$ activated a greater proportion of NK and T cell populations when compared to the GS-9620 concentration of $0.15 \mathrm{mg} / \mathrm{kg}$.

At the TLR7 agonist doses used, we found that the activation of peripheral blood T cells in the TLR7 agonist-treated rhesus macaques was primarily in the effector memory subpopulation $\left(\mathrm{CD} 95^{+} \mathrm{CD} 28^{-}\right)$, with limited activation of naïve $\left(\mathrm{CD} 95^{-} \mathrm{CD} 28^{+}\right)$or central memory $\left(\mathrm{CD} 95^{+} \mathrm{CD} 28^{+}\right) \mathrm{T}$ cell populations (Fig. 4). Similarly, specific subpopulations of NK cells defined as $\mathrm{CD} 16^{+}$and $\mathrm{CD} 16^{-} \mathrm{CD} 56^{-}$were preferentially activated over CD16 ${ }^{-} \mathrm{CD} 56^{+} \mathrm{NK}$ cells (fig. S8A). Conversely, naïve B cells (CD27-) tended to be activated more robustly than memory $\left(\mathrm{CD} 27^{+}\right) \mathrm{B}$ cells, as measured by elevated CD38 expression (fig. S8B).

Consistent with the results observed in study 1, we found that the repeat dosing of GS-986 or GS-9620 induced transient viremia in all treated rhesus macaques (doses 3 to 10) and that viral reactivation was detectable from the 3rd to 10th dose (Fig. 5). However, in the second study using lower doses of the TLR7 agonists, the plasma viral blip frequency was reduced and variable. In each monkey, we analyzed the total amount of SIV RNA released in the plasma within 72 hours after each TLR7 agonist dose by calculating the AUC. Total plasma SIV RNA (in both studies) peaked after the fifth TLR7 agonist dose and declined thereafter (fig. S9). After 10 doses of GS-986 and GS-9620, all rhesus macaques underwent a 3-month pause without TLR7 agonist dosing. We then resumed vehicle, GS-986, or GS-9620 (0.05 $\mathrm{mg} / \mathrm{kg}$ ) dosing for an additional nine doses, again every other week. Similar to the first phase of study 2, rapid activation of T, B, and NK cell subsets was observed (Fig. 4 and fig. S8, A and B). During the second phase of dosing, only a single viral blip was observed in one animal. 
Motivated by the findings of study 1, SIV DNA was again quantified and showed a reduction in $\mathrm{CD} 4^{+}$memory $\mathrm{T}$ cells from all TLR7 agonist-treated rhesus macaques but a minimal change for control animals (Fig. 6A). Repeated TLR7 agonist dosing was associated with viral DNA reductions in the blood and tissues; this trend was not observed in control animals. The most significant decrease in SIV DNA was observed in either $\mathrm{T}_{\mathrm{TM}}$ or $\mathrm{T}_{\mathrm{EM}}$ subsets in most rhesus macaques treated with TLR7 agonists (Fig. 6B). SIV DNA in $\mathrm{T}_{\mathrm{CM}}$ was variable in most TLR7 agonist-treated rhesus macaques; however, there was a reduction in this value measured in $\mathrm{T}_{\mathrm{CM}}$ from two animals. We then conducted a combined statistical analysis for all TLR7 agonist- treated rhesus macaques. Significant reductions in SIV DNA in both PBMCs (0.79 log median, $P=0.004)$ and GMMCs ( $0.33 \log$ median, $P=$ $0.027)$ were detected, and a trend toward significance in LNMCs was also observed ( 0.33 $\log$ median, $P=0.054$; fig. S6).

Plasma IFN-a concentrations were also analyzed in all animals from studies 1 and 2 (fig. S3B). In the first study, all four rhesus macaques treated with increasing doses of GS-986 had detectable plasma IFN- $a$ at 24 hours after each dose (fig. S3A). As expected, in the second study using reduced pharmacodynamic doses of the TLR7 agonists, only one animal [receiving GS-986 $(0.1 \mathrm{mg} / \mathrm{kg})$ ] out of all nine TLR7 agonist-treated animals had appreciable plasma IFN- $a$ in the initial 10 doses. In the subsequent nine doses, after the 3month rest period, there was transient but detectable induction of IFN-a, with the greatest changes in animals receiving GS-986 (0.1 mg/kg) compared to the initial 10 doses (fig. S3B).

To confirm that the TLR7 agonists were eliciting biological activity in study 2, we evaluated expression of the IFN-stimulated gene (ISG) mRNAs ISG15, Mx 1 , and $O A S 1$. All animals treated with a TLR7 agonist showed transient dose-dependent induction of all three ISG mRNAs (fig. S10). The peak induction of each ISG mRNA in the GS-986- and GS-9620 $(0.15 \mathrm{mg} / \mathrm{kg})$-treated groups was observed within 24 hours. The GS-986-treated group showed the most robust induction of ISGs. However, these returned to baseline within 72 hours or before the next dose.

We also assessed the pattern of cytokine expression resulting from TLR7 agonist administration in both studies. In study 1 , where animals received increasing IFN-ainducing doses of GS-986, multiple plasma cytokines and chemokines were transiently produced after administration of the TLR7 agonist that were found to be proportional to dose. Peak production of cytokines and chemokines, with the exception of RANTES, was observed in most rhesus macaques within 24 to 48 hours after GS-986 dosing (fig. S11A). The most robustly induced plasma cytokine after TLR7 agonist treatment in this study was interleukin-1 receptor antagonist (IL-1RA), a marker of immune activation and regulation. IFN-inducible T cell a chemoattractant (I-TAC) was also readily inducible by each TLR7 dose. We observed an increase in the concentration of both IL-1RA and I-TAC 24 hours after each TLR7 agonist dose compared to baseline (fig. S11, A and B).

In study 2, we found that treatment with GS-986 or GS-9620 $(0.15 \mathrm{mg} / \mathrm{kg})$ transiently induced cytokines (or chemokines), but rhesus macaques receiving the lower GS-9620 dose $(0.05 \mathrm{mg} / \mathrm{kg})$ had very low or undetectable plasma cytokine concentrations, demonstrating 
that cytokine production was proportional to GS-9620 dose (fig. S11C). Consistent with study 1, IL-1RA and I-TAC were highly induced after TLR7 agonist treatment. In the subsequent nine doses, after the 3-month rest period, although there was weak induction of IL-1RA after each TLR7 dose, overall fold changes were decreased in animals receiving GS-986 $(0.1 \mathrm{mg} / \mathrm{kg})$ compared to the initial 10 doses (fig. S11D).

To assess changes in the size of the inducible SIV reservoir longitudinally after TLR7 agonist treatment, we used a modified in vitro viral outgrowth assay (see Materials and Methods) amenable to the limitations in blood draw volumes for rhesus macaques. PBMCs were isolated from rhesus macaques before and after treatment, and LNMCs after treatment, and were activated in vitro using ConA. Six days after activation, SIV RNA was isolated from culture supernatants and quantified by reverse transcription polymerase chain reaction (RT-PCR).

We observed longitudinal reductions in the amount of reactivated SIV produced from PBMCs isolated from most TLR7 agonist-treated animals (Fig. 6C). However, SIV RNA produced from control monkeys remained essentially unchanged over time. Two TLR7 agonist-treated animals 177-10 (GS-9620 $0.15 \mathrm{mg} / \mathrm{kg}$ group) and 344-10 (GS-986 0.1 $\mathrm{mg} / \mathrm{kg}$ group) were completely negative for ConA-induced SIV RNA induction in both PBMC and LNMC samples taken after the 10th and 19th TLR7 agonist dose, respectively (Fig. 6C).

To assess whether these reductions in the cell-associated SIV reservoir were predictive of viral rebound, ART was discontinued for all study 2 animals. Rebound occurred in most rhesus macaques within 7 to 10 days of ART cessation (Fig. 6D). Strikingly, the same two rhesus macaques, which were negative in both PBMCs and LNMCs for ConA-inducible SIV, did not rebound. In both animals, plasma viremia has remained undetectable for more than 700 days after stopping ART. We also observed that two viremic rhesus macaques from TLR7 agonist-treated groups showed continual declines in their plasma viral RNA after day 100.

To address whether this absence of rebound viremia was a result of either immune control or reservoir clearance, we conducted a series of in vitro experiments. We first evaluated the development of anamnestic $\mathrm{T}$ cell responses after ART cessation by measuring the frequency of virus-specific cytokine-producing $\mathrm{T}$ cells on the day of ART release (day 0) and on days 35 and 177 after ART was halted. Rhesus macaques that had recrudescent viremia developed clear anamnestic SIV-specific T cell responses, whereas aviremic rhesus macaques did not respond to SIV peptide stimulation (fig. S12).

We next performed an in vitro viral outgrowth assay using PBMCs isolated at day 177 after ART cessation from two aviremic rhesus macaques (177-10 and 344-10) and also from two viremic animals (162-09 and 305-10) to serve as positive controls. After 6 days of stimulation, virus was readily detectable in PBMCs from viremic animals, yet animals 177-10 and 344-10 remained completely negative for SIV (fig. S13A).

We next assessed whether SIV could be cultured from the PBMCs and initiate infection in CEMx 174 cells in the absence of $\mathrm{CD} 8^{+} \mathrm{T}$ cells. We cocultured $1 \times 10^{6} \mathrm{CD}^{+} \mathrm{T}$ cell- 
depleted PBMCs with $5 \times 10^{6}$ CEMx174 cells. Virus production in culture supernatants was monitored by RT-PCR of samples taken on days 5, 9, and 14 after coculture. We were unable to detect virus from PBMCs isolated from the two aviremic animals, whereas PBMCs from the two viremic rhesus macaques initiated viral replication in CEMx174 cells (fig. S13B).

To determine whether any replication-competent virus remained in our remission animals, we performed an in vivo antibody-mediated depletion of $\mathrm{CD} 8^{+}$lymphocytes in both aviremic rhesus macaques (177-10 and 344-10) and the two viremic rhesus macaques (288-10 and 295-10). After infusion, in vivo $\mathrm{CD}^{+}$lymphocytes were rapidly depleted in all rhesus macaques by 3 days after antibody treatment (fig. S14 and Fig. 7A), and CD8 ${ }^{+}$cells were completely cleared from the peripheral blood for at least 17 days. In the absence of $\mathrm{CD}^{+}$cells, the two viremic rhesus macaques displayed a rapid spike in plasma viral RNA. However, neither of the two aviremic animals had any detectable plasma virus at any point during $\mathrm{CD}^{+}$lymphocyte depletion (Fig. 7A).

Finally, to confirm whether the lack of detectable viremia in our remission animals was due to the clearance of replication-competent SIV or immune-mediated viral suppression, we performed adoptive cell transfer studies (see Materials and Methods). In two separate transfer experiments, we infused samples obtained before or after TLR7 treatment into four naïve rhesus macaques ( $n=2$ per group). In the first transfer, we used about 50 million frozen PBMCs and LNMCs obtained from each animal (that is, 177-10 and 344-10) after ART, just before TLR7 agonist treatment. PBMCs and LNMCs from each rhesus macaque in remission were combined and then infused into two naïve recipient macaques. This adoptive transfer readily initiated de novo infection by day 7 after transfer (Fig. 7B). In the second transfer, fresh PBMCs and lymph nodes from day 448 post-ART cessation were isolated within 2 hours of biopsy from the two macaques in remission (177-10 and 344-10). These fresh PBMC and LNMC mixtures from each aviremic animal were transfused into two naïve recipient macaques. Despite infusion of more than $~ 120$ million fresh PBMCs and LNMCs from each aviremic rhesus macaque, we failed to initiate infection in either naïve recipient macaque (Fig. 7B). The two recipient monkeys were monitored for 28 days after infusion, with no evidence of detectable viremia.

We next used modeling of viral dynamics to gain further insight into the effects of treatment with TLR7 agonists (fig. S15A). We found no significant differences in either set point viremia or time to rebound between treatment and control animals in either study (fig. S15B). However, examining the kinetics of rebound after ART cessation, we found that the TLR7 agonist-treated macaques that rebounded showed decreased viral reactivation rates (study $1, P=0.03$; study 2, $P=0.05$; pooled, $P=0.01)$ and increased viral growth rates $(P=$ $0.02, P=0.05$, and $P=0.03$ ) compared to a pooled control group (fig. S15, C and D). A summary of the differences in rebound kinetics between treated and control rhesus macaques is shown in fig. S15 (E and F). Our analysis suggested that TLR7 agonist treatment may have reduced the SIV reservoir even in animals that did rebound after ART cessation.

We also predicted the distribution of rebound times as a function of the reduction in the reservoir size, using a separate stochastic model of viral reactivation and rebound. Survival curves show the predicted percentage of animals that had not yet rebounded as a function of 
time after ART cessation (fig. S15G). For the two aviremic rhesus macaques, we used this model to estimate that the SIV reservoir had been reduced by more than 1400-fold by TLR7 agonist treatment (95\% confidence interval, 110 to 32,000 ) and to explain a greater than 2year delay in SIV rebound, assuming that reservoir reduction was the sole mechanism for control of any recrudescent viremia (fig. S15H). Given that CD8 $8^{+}$lymphocyte depletion did not lead to loss of viral control in these animals and that adoptive transfer of cells did not induce viremia in naïve recipients, we believe that this is reasonable. Furthermore, modeling of cumulative viral blip trajectories suggested that the viral blip sizes induced by TLR7 agonist treatment were compatible with meaningful reductions in the size of the latent SIV reservoir (that is, $\sim 1 \%$ of all SIV DNA-positive cells became reactivated over the whole treatment course). Model fit parameters for individual animals are shown in fig. S16.

\section{DISCUSSION}

We demonstrate in two independent rhesus macaque studies the ability of TLR7 agonist treatment to induce potent immune responses along with an increase in expression of select IFN-regulated antiviral genes and cytokines. Similarly, TLR7 agonist treatment induced transient viremia that was concurrent with immune activation in the SIV-infected rhesus macaques. Ultimately, the combination of TLR7 agonist-induced immune potentiation and transient viremia may have resulted in the observed reductions in the viral reservoir in our nonhuman primate model of HIV-1 latency.

In these studies, we used a stringent animal model involving a pathogenic SIVmac251 isolate and excluded rhesus macaques with MHC alleles known to confer enhanced SIV control. We determined the proportion of rhesus macaques that could be expected to spontaneously control SIV after ART discontinuation. Not one case of spontaneous viral remission was observed by our group in MHC-defined (A*01-, B*08-, B*17-negative) animals that started ART relatively late (at day 65 after SIVmac251 infection) or even in groups of animals administered ART as early as day 3 after infection in which the SIV reservoir was much smaller (22).

Despite the stringency of our SIV persistence macaque model, there are notable limitations to our study. Several practical considerations limited the number of rhesus macaques used for treatment and control arms; thus, the overall power to discriminate significance in certain analyses was reduced. SIV-infected animals on ART are similar, but certainly not identical, to HIV-infected patients on ART, with notable differences between SIV and HIV viruses and between macaque and human hosts. One important difference is that HIV-1 patients typically are maintained on potent ART regimens for much longer periods than were achieved in this study. These extended periods of ART treatment in human patients are expected to have an impact on the HIV-1 reservoir.

Our data show that TLR7 agonists exhibit biological effects in vivo that are consistent with the induction of transient viremia and SIV DNA reductions in most SIV-infected animals after TLR7 agonist treatment. However, the precise mechanisms by which these TLR agonists induce transient viremia remains to be fully defined. We have identified several biological correlates that identify this phenomenon, and we posit that these cytokine 
signatures, in concert with repeated TLR7 agonist-induced activation of CD4 ${ }^{+} \mathrm{T}$ cell memory subsets, may have led to the SIV RNA that we detected in the plasma.

Dosing with the TLR7 agonists was well tolerated throughout both studies. As each TLR7 agonist was orally dosed, exposure in the gut was expected to be higher, possibly leading to enhanced activation of $\mathrm{CD} 4^{+} \mathrm{T}$ cells in these tissues. Specifically, formulated TLR7 agonist absorption and its effects are expected to be proportionally higher in the gut, because both agonist compounds have high absorption properties in the gastrointestinal (GI) tract and show only moderate clearance rates during the first phase of hepatic metabolism. Although these properties limit systemic exposure of TLR7 agonists after oral administration, they enhance drug exposure in the GI tract and the liver $(18,19,24)$. Therefore, it is not surprising that the effects of these agonists appeared to be enhanced in the gut, as observed in the reduction of SIV DNA in $\mathrm{CD} 4^{+} \mathrm{T}$ cells from GMMCs. This latter observation was also consistent with the increases in IL-1RA observed after each TLR7 agonist treatment, signifying high cellular activation in the gut. Thus, it seems plausible that a proportion of the viremia that was detected after TLR7 agonist treatment may have arisen, at least initially, from the gut compartment. Unfortunately, our sequence analysis could not discriminate a tissue-specific SIV sequence to confirm this possibility. However, the modulation of IL-1RA in both studies may have been broadly concordant with the enhanced clearance of provirus from the GMMCs in most animals and particularly those receiving higher TLR agonist doses.

We also observed a strong association between expression of I-TAC (CXCL11) and the induction of transient viremia as well as the observed immune activation and presumed effector recruitment to multiple (reactivated) sites of infection, including the lymph nodes (25). In this context, I-TAC may also serve as a signature or "trigger" cytokine for the induction of transient viremia. A positive correlation has been observed between the GS-9620-induced peak of IP-10 (CXCL10), I-TAC (CXCL11), and SIV reactivation. However, we cannot discount the role of other innate and adaptive mediators potentiated by TLR7 agonist treatment in the induction of viremia. These same responses may have aided the clearance of reactivated SIV-infected cells.

These biological effects of TLR7 agonists appear to be consistent with the potential to reduce viral DNA during ART, although complete remission was observed only in a subset of animals after ART discontinuation. In the two aviremic rhesus macaques, it is noteworthy that durable remission was only achieved with a complete clearance of in vitro inducible virus from both the PBMCs and LNMCs. Animals that had otherwise displayed reservoir reductions in the blood, lymph nodes, or gut, but had inducible SIV in the lymph nodes, recrudesced once ART was discontinued. These "rebounder" observations were predicted based on our modeling analysis. However, many of the TLR7 agonist-treated rhesus macaques that exhibited viral rebound also showed longitudinal reductions in viral set point, potential evidence of a therapeutic effect.

A detailed assessment of the virological and immunological differences between viremic rhesus macaques and rhesus macaques in remission after TLR7 agonist administration revealed significant reductions in SIV DNA in $\mathrm{T}_{\mathrm{CM}}$ and $\mathrm{T}_{\mathrm{TM}}$ populations from PBMCs and 
$\mathrm{T}_{\mathrm{CM}}$ from LNMCs. These SIV DNA reductions in memory $\mathrm{T}$ cell subsets were concurrent with increases in I-TAC production during TLR7 agonist doses 1 to 10 and with proportional increases in mRNA expression of ISG15 and MXI. Although these ISGs were induced in all rhesus macaques after TLR7 agonist treatment (in a dose-response manner), increased expression of both ISG15 and Mx1 was noted in the rhesus macaques that ultimately became aviremic.

Our model predictions of cumulative viral reactivation events suggested that repeated episodes of transient viremia induced by TLR7 agonist treatment were consistent with the observed reductions in the latent SIV reservoir and help to explain the now greater than 24month period of undetectable SIV in two rhesus macaques. This prediction assumes that reservoir reduction is the sole mechanism for lack of recrudescent viremia. The possibility of this being the case is partially corroborated by several observations favoring SIV clearance as the dominant mechanism over immunological suppression of SIV. First, remission animals exhibited no SIV-specific cellular immune responses after release from ART. Second, long-term $\mathrm{CD} 8^{+} \mathrm{T}$ lymphocyte depletion did not result in any recrudescent viremia. Third, the adoptive transfer of cells (PBMCs and LNMCs) from aviremic rhesus macaques did not induce viremia in naïve rhesus macaque recipients. Fourth, neutralizing antibodies could have afforded some level of immunological control, but the antibody profiles evaluated had waned to undetectable levels in most animals during ART, as expected (26). Neutralizing antibodies were also assessed at various times after ART release, and neither of the two remission rhesus macaques mounted any detectable neutralizing antibody responses after ART cessation. Finally, a sustained viral remission of greater than 2 years, absent ART, and an immune correlate of control could only be sustained by a near-complete clearance of all of the replication-competent viral reservoir. Therefore, we believe our assumption favoring SIV reservoir reduction is reasonable but requires additional confirmatory experimentation. In conclusion, these findings support the further evaluation of TLR7 agonists for their impact on the SIV and HIV viral reservoir eradication.

\section{MATERIALS AND METHODS}

\section{Study design}

These experiments were designed to investigate whether the administration of TLR7 agonists could perturb an established latent viral reservoir in SIV-infected rhesus macaques on ART. Twenty-one Indian-origin, outbred, young adult, male, specific pathogen-free rhesus macaques (Macaca mulatta) that did not express the class I alleles Mamu- $A^{*} 01$, Mamu- $B^{*} 08$, and $M a m u-B^{*} 17$ associated with enhanced virus control were housed at BIOQUAL Inc. (27-29). Animals used for the studies were infected using a repeated lowdose intrarectal challenge with the SIVmac251 strain. Animals were assigned to individual study arms to balance the following parameters across groups: pre-ART viral burden, SIV viral load at $\mathrm{ART}$ initiation, $\mathrm{CD} 4^{+}$and $\mathrm{CD} 8^{+} \mathrm{T}$ cell counts, $\mathrm{CD} 4^{+} / \mathrm{CD} 8^{+} \mathrm{T}$ cell ratio, and animal weights. The preformulated ART cocktail contained two reverse transcriptase inhibitors, TFV $(20 \mathrm{mg} / \mathrm{ml})$ and FTC $(50 \mathrm{mg} / \mathrm{ml})$, plus the integrase inhibitor DTG $(2.5 \mathrm{mg}$ / $\mathrm{ml})$. This ART cocktail was administered once daily at $1 \mathrm{ml} / \mathrm{kg}$ body weight via the subcutaneous route as described. The TLR7 agonists GS-986 and GS-9620 were provided 
by Gilead Sciences. All TLR7 agonist preparations were endotoxin-free. Various formulated concentrations of GS-986 or GS-9620 were administered to macaques every other week at the dose concentrations described. Macaques were bled up to four times per week to assess immunological parameters or viral RNA. Tissues including lymph node and colorectal mucosa were biopsied before, and after the last dose, of the TLR7 agonists to measure cellassociated provirus. Two weeks after the last dose, ART was discontinued in all groups to monitor viral rebound.

We included all animals in all analyses. Technical staff were blinded during data acquisition and unblinded for data analysis. With 21 macaques used in this study, we had at least $80 \%$ statistical power with one-sided type I error of $5 \%$ to detect an effect (measurable viral reactivation and alteration from an established baseline of SIV reservoir in blood and tissues) of $80 \%$ or greater in animals tested. The animal studies described were approved by the appropriate Institutional Animal Care and Use Committee.

\section{Lymphocyte staining and analysis}

PBMCs were isolated by Ficoll density gradient centrifugation. About $0.5 \times 10^{6}$ PBMCs were stained with each of the following three panels of antibodies: NK cell panel: CD3 (SP34-2), CD8 (SK1), NKG2A (Z199, Beckman Coulter), CD16 (3G8), CD56 (N901, Beckman Coulter), and CD69 (TP1.55.3, Beckman Coulter); B cell panel, CD3, CD20 (L27), CD38 (OKT10, Nonhuman Primate Reagents Resource Program), CD40 (5C3), CD69, CD95 (DX2), CD27 (O323, eBioscience), and CD86 [2331 (FUN-1)]; T cell panel: CD3, CD4 (L200), CD8, CD14 (M5E2), CD95 (DX2), CD28 (CD28.2, eBioscience), CD69, and CD20. All antibodies are from BD Biosciences unless otherwise indicated. All events were gated first on FSC singlets and then lymphocytes. B cells were identified as $\mathrm{CD}^{-} \mathrm{CD} 20^{+}$, and $\mathrm{CD} 27$ was used to define naïve $\left(\mathrm{CD} 27^{-}\right)$and memory $\left(\mathrm{CD} 27^{+}\right)$subsets

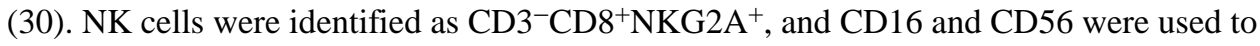
define subsets $(31,32)$. $\mathrm{CD} 4^{+}$and $\mathrm{CD} 8^{+} \mathrm{T}$ cells were identified as $\mathrm{CD}^{+} \mathrm{CD} 14^{-}$, and $\mathrm{CD} 28$ and CD95 were used to define subsets (33). CD69 was measured as a percent of lymphocyte population of interest. CD38 was measured as the geometric mean fluorescence (GMF) of the total cell population of interest. To account for any technical fluctuations in fluorescence, CD38 GMF was normalized by dividing by the background CD38 [phycoerythrin (PE)] GMF of a CD38-negative population in the corresponding sample.

\section{Proviral DNA assays}

Lymph node and GI mucosal biopsies were processed as single-cell suspensions essentially as previously described (22). Tissue-specific proviral DNA was quantitated as previously reported (34). Total cellular DNA was isolated from $5 \times 10^{6}$ cells using a QIAamp DNA Blood Mini kit (Qiagen). The absolute quantification of viral DNA in each sample was determined by quantitative PCR (qPCR) using primers specific to a conserved region (SIVmac239). All samples were directly compared to a linear virus standard and the simultaneous amplification of a fragment of human GAPDH gene. The sensitivity of linear standards was compared against the 3D8 cell line as a reference standard as described (35). All PCR assays were performed with 100 and $200 \mathrm{ng}$ of sample DNA. 


\section{$\mathrm{CD4}^{+} \mathrm{T}$ cell memory subset sorting}

Cryopreserved samples of PBMC, lymph node, and colorectal biopsies were thawed at $37^{\circ} \mathrm{C}$ in RPMI 1640 containing 10\% fetal bovine serum (FBS) and benzonase (Millipore) at 50 U/ml. Cells were resuspended in 1× phosphate-buffered saline (PBS) containing LIVE/ DEAD Fixable Aqua Dead Cell Stain (Life Technologies) for $20 \mathrm{~min}$ at room temperature in the dark. Cells were washed and resuspended in wash buffer containing the following fluorescently conjugated antibodies: CD45 (D058-1283), CD28 (CD28.2, Beckman Coulter), CD4 (L200), CCR7 (3D12), CD95 (DX2), CD3 (SP34-2), and CD8 (SK1). After $15 \mathrm{~min}$ in the dark, cells were washed and resuspended in ice-cold $1 \times$ PBS. Cells were sorted using a BD FACSAria II. Sorted CD4 ${ }^{+} \mathrm{T}$ cells were FSC singlets, live, $\mathrm{CD} 5^{+} \mathrm{CD}^{+}{ }^{+} \mathrm{CD} 4^{+} \mathrm{CD} 8^{-}$lymphocytes, and subsets were defined as follows: naïve $\left(\mathrm{CD} 95^{-} \mathrm{CD} 28^{+} \mathrm{CCR} 7^{+}\right)$, central memory $\left(\mathrm{CD} 95^{+} \mathrm{CD} 28^{+} \mathrm{CCR} 7^{+}\right)$, transitional memory $\left(\mathrm{CD} 95^{+} \mathrm{CD} 28^{+} \mathrm{CCR} 7^{-}\right)$, and effector memory $\left(\mathrm{CD} 95^{+} \mathrm{CD} 28^{-}\right)$. All antibodies are from BD

Biosciences unless otherwise indicated. In study 1 , sorted memory populations were pooled into a single memory population and subject to proviral DNA analyses due to limiting cell numbers.

\section{Virus sequencing}

Virus sequencing of SIV recovered from plasma "blips" was performed essentially as described (23). Viral complementary DNA (cDNA) was diluted in 96-well plates to yield fewer than $30 \%$ wells positive for amplification to ensure that positive amplifications were a result of a single cDNA. Amplicons from cDNA dilutions resulting in less than $30 \%$ positive wells were sequenced at the Dana-Farber/Harvard Cancer Center DNA Resource Core. Raw cDNA sequence data were assembled using Gene Codes Sequencher 4.8 DNA sequencing software. All assembled sequence contigs were manually corrected for individual ambiguous nucleotide errors and further quality-controlled to exclude any amplicons derived from multiple templates. Nucleotide alignments were made using the Gene Cutter algorithm as described below (www.hiv.lanl.gov/content/sequence/GENE_CUTTER/cutter.html).

\section{Viral phylogenetic analysis}

The gag and env codon sequence alignments were manually reviewed after automatic alignment with Gene Cutter (www.hiv.lanl.gov/content/sequence/GENE_CUTTER/ cutter.html). Sequences were stratified by macaque, and BioPerl (v1.006924) inferred a founder consensus sequence from plasma-derived variants sampled before treatment. A test for homogeneous infection, based on a null model of random sequence evolution in acute infection, compared the distribution of Hamming distances among sequences sampled from plasma before ART for a Poisson distribution $(36,37)$. The Hypermut utility (v2; www.hiv.lanl.gov/content/sequence/HYPERMUT/hypermut.html) identified sequences enriched for APOBEC-induced hypermutations relative to the founder reference sequence. For each animal, PhyML (v3) computed a phylogeny using the GTR nucleotide substitution model (38) and a four-category discrete approximation to a gamma distribution of evolutionary rates across sites, with an additional term for invariant sites (39). Parameters were inferred by maximum likelihood jointly with tree topology optimization with the resulting trees rooted on founder sequences. Newick Utilities (v1.6) summarized 
evolutionary distances to the founder sequence and omitted the sequences that exactly matched the founder by pruning from the tree. Trees were similarly pruned to show quasispecies development by cumulative stratification into groups sampled before, before/ during, and before/during/after treatment. The $\mathrm{R}$ package ape rendered trees (v3.4).

\section{Ex vivo virus outgrowth assay}

PBMCs were isolated using a Ficoll-Hypaque density gradient and then resuspended at $2.0 \times$ $10^{6}$ cells/ml in RPMI 1640 medium supplemented with $10 \%$ heat-inactivated FBS, penicillin, streptomycin, and $100 \mathrm{nM}$ raltegravir. PBMCs were then seeded into culture plates at $4 \times 10^{6}$ cells per well with or without ConA stimulation. Cell cultures were then incubated at $37^{\circ} \mathrm{C}$ in a humidified $5 \% \mathrm{CO}_{2}$ atmosphere for 6 days. After 6 days in culture, cell-free supernatant was collected for the measurement of SIV RNA by qRT-PCR.

\section{In vitro coculture with CEMx174 cells}

$\mathrm{CD}^{+} \mathrm{T}$ cells were depleted from freshly ficolled PBMCs using Miltenyi's CD8 Microbead Kit for nonhuman primates according to the manufacturer's instructions and quantified using the flow cytometry-based cell counter Guava easyCyte (EMD Millipore). CEMx174 cells (5 $\times 10^{6}$ ) were incubated at $37^{\circ} \mathrm{C}$ with $1 \times 10^{6} \mathrm{CD} 8^{+} \mathrm{T}$ cell-depleted PBMCs in $3 \mathrm{ml}$ of culture medium for 48 hours. Culture medium was added to up to $10 \mathrm{ml}$ on day 3 , and cells were split twice per week.

\section{In vivo CD8+ lymphocyte depletion}

Rhesus macaques were depleted of $\mathrm{CD} 8^{+}$lymphocytes $\left(\mathrm{CD} 8^{+} \mathrm{T}\right.$ cells and NK cells) using the monoclonal antibody MT807R1 (Nonhuman Primate Reagent Resource) as previously described (40) using the following dosing schedule: on day $0,10 \mathrm{mg} / \mathrm{kg}$ was delivered subcutaneously, and on days 3,7 , and $10,5 \mathrm{mg} / \mathrm{kg}$ was delivered intravenously. CD4 and CD8 lymphocytes were monitored twice weekly for the first 3 weeks and then weekly for the remaining monitoring period. Whole blood was stained with the antibodies CD4-PerCPCy5.5 (L200, BD Biosciences), CD8-PE (DK25, Dako), and CD3-APC (SP34.2, BD Biosciences). The anti-CD8 antibody clone DK25 has been previously determined to not be blocked by bound MT807R1 (41). Red blood cells were lysed using a TQ-Prep (Beckman Coulter), fixed in $2 \%$ formaldehyde, acquired on a FACSCalibur (BD Biosciences), and analyzed using FlowJo Software. Complete blood counts (CBCs) were analyzed on a Siemens ADVIA 120. Frequencies of $\mathrm{CD} 8^{+}$lymphocytes per volume blood were calculated using the percent $\mathrm{CD} 8^{+}$lymphocytes, determined by flow cytometry, and the frequencies of total lymphocytes, determined by the CBC.

\section{In vivo adoptive cell transfer}

For adoptive transfer experiments, fresh or frozen PBMCs and LNMCs were used. For adoptive cell transfer before TLR7 agonist dosing, frozen PBMCs and LNMCs were used. For samples after therapy, fresh PBMCs and LNMCs were isolated from two remission rhesus macaques (at day 445 after ART stop). Cells were washed three times in PBS and then infused into naïve rhesus macaques by the intravenous route. Two rhesus macaques received either total $5.1 \times 10^{7}$ or $5.9 \times 10^{7}$ of cell infusions (before TLR7 agonist treatment), 
and the other two rhesus macaques received infusions of approximately 120 million cells (isolated on day 445 after ART stop).

\section{Intracellular cytokine staining}

Measurement of IFN- $\gamma$ on $\mathrm{CD} 4^{+}$and $\mathrm{CD} 8^{+} \mathrm{T}$ cells from fresh and cryopreserved PBMCs cells was performed as previously described (42). Thawed PBMCs were rested at $37^{\circ} \mathrm{C}$ for 4 hours before stimulation. About $3 \times 10^{6}$ cells were stimulated with either dimethyl sulfoxide alone (unstimulated) or overlapping peptide pools $(2 \mu \mathrm{g} / \mathrm{ml})$ covering the entire SIVmac239 Gag protein (National Institutes of Health AIDS Reagent Program, catalog no. 6204) and anti-CD49d antibodies ( $1 \mu \mathrm{g} / \mathrm{ml}$; BD Biosciences). The following conjugated antibodies and staining reagents were used for surface staining: CD4 (L200), CD95 (DX2), CD28 (L293), CD8 (SK1), and LIVE/DEAD Fixable Yellow Dead Cell Stain (Invitrogen). The following conjugated antibodies were used during intracellular staining: CD3 (SP34-2), IFN- $\gamma$ (B27), and CD69 (TP1.55.3, Beckman Coulter). All antibodies are from BD Biosciences unless indicated otherwise. Value of percent IFN- $\gamma$-positive cells in unstimulated samples was subtracted from the corresponding value of stimulated samples.

\section{Statistical analyses}

Analyses of virological or immunological data at study entry were performed using Wilcoxon signed-rank tests. Transformed $\log _{10}$ SIV RNA copies $/ \mathrm{ml}$ of plasma were calculated using GraphPad Prism (version 6.0). Comparisons of grouped variables and changes in values after treatment within groups were analyzed using a Wilcoxon signed-rank test and a Wilcoxon matched pairs signed-rank test, respectively. $P$ values were adjusted for multiple comparisons when more than two groups were compared. Changes in cytokine and chemokine concentrations in plasma after TLR7 agonist treatment and its significance were displayed using a volcano plot. R package (version 3.3.0) was used to generate heat maps. Power calculations and two-sample $t$ test for equality of proportions with continuity correction were conducted using G*Power software (www.gpower.hhu.de).

\section{Supplementary Material}

Refer to Web version on PubMed Central for supplementary material.

\section{Acknowledgments}

We thank J. Harrison, C. Gittens, J. Yalley-Ogunro, H. Anderson, and W. Wagner for expert animal husbandry and care. $\mathrm{CD}^{+}{ }^{+}$T cell-depleting antibody, MT807R1, and anti-CD38-PE were obtained from the NIH Nonhuman Primate Reagent Resource supported by grants HHSN272200900037C and OD010976.

Funding: We acknowledge support from Gilead Sciences. This work was supported by National Institute of Allergy and Infectious Diseases (NIAID) grant AI126617 and co-funded by National Institute on Drug Abuse, National Institute of Mental Health, National Institute of Neurological Disorders and Stroke. NIH grant DP5OD019851 was awarded to A.L.H., and NIAID grants AI091514, AI122942, AI127089, AI131365, and AI007387 were awarded to J.B.W.

\section{REFERENCES AND NOTES}

1. Finzi D, Blankson J, Siliciano JD, Margolick JB, Chadwick K, Pierson T, Smith K, Lisziewicz J, Lori F, Flexner C, Quinn TC, Chaisson RE, Rosenberg E, Walker B, Gange S, Gallant J, Siliciano 
RF. Latent infection of $\mathrm{CD}^{+}{ }^{+} \mathrm{T}$ cells provides a mechanism for lifelong persistence of HIV-1, even in patients on effective combination therapy. Nat Med. 1999; 5:512-517. [PubMed: 10229227]

2. Finzi D, Hermankova M, Pierson T, Carruth LM, Buck C, Chaisson RE, Quinn TC, Chadwick K, Margolick J, Brookmeyer R, Gallant J, Markowitz M, Ho DD, Richman DD, Siliciano RF. Identification of a reservoir for HIV-1 in patients on highly active antiretroviral therapy. Science. 1997; 278:1295-1300. [PubMed: 9360927]

3. Gandhi RT, Zheng L, Bosch RJ, Chan ES, Margolis DM, Read S, Kallungal B, Palmer S, Medvik K, Lederman MM, Alatrakchi N, Jacobson JM, Wiegand A, Kearney M, Coffin JM, Mellors JW, Eron JJ. AIDS Clinical Trials Group A5244 team. The effect of raltegravir intensification on low-level residual viremia in HIV-infected patients on antiretroviral therapy: A randomized controlled trial. PLOS Med. 2010; 7:e1000321. [PubMed: 20711481]

4. Margolis DM. Eradication therapies for HIV infection: Time to begin again. AIDS Res Hum Retroviruses. 2011; 27:347-353. [PubMed: 21314240]

5. Margolis DM. Mechanisms of HIV latency: An emerging picture of complexity. Curr HIV/AIDS Rep. 2010; 7:37-43. [PubMed: 20425056]

6. Archin NM, Espeseth A, Parker D, Cheema M, Hazuda D, Margolis DM. Expression of latent HIV induced by the potent HDAC inhibitor suberoylanilide hydroxamic acid. AIDS Res Hum Retroviruses. 2009; 25:207-212. [PubMed: 19239360]

7. Archin NM, Eron JJ, Palmer S, Hartmann-Duff A, Martinson JA, Wiegand A, Bandarenko N, Schmitz JL, Bosch RJ, Landay AL, Coffin JM, Margolis DM. Valproic acid without intensified antiviral therapy has limited impact on persistent HIV infection of resting $\mathrm{CD}^{+}{ }^{+} \mathrm{T}$ cells. AIDS. 2008; 22:1131-1135. [PubMed: 18525258]

8. Archin NM, Cheema M, Parker D, Wiegand A, Bosch RJ, Coffin JM, Eron J, Cohen M, Margolis DM. Antiretroviral intensification and valproic acid lack sustained effect on residual HIV-1 viremia or resting CD4 ${ }^{+}$cell infection. PLOS ONE. 2010; 5:e9390. [PubMed: 20186346]

9. Sahu GK, Cloyd MW. Latent HIV in primary T lymphocytes is unresponsive to histone deacetylase inhibitors. Virol J. 2011; 8:400. [PubMed: 21838863]

10. Keedy KS, Archin NM, Gates AT, Espeseth A, Hazuda DJ, Margolis DM. A limited group of class I histone deacetylases acts to repress human immunodeficiency virus type 1 expression. J Virol. 2009; 83:4749-4756. [PubMed: 19279091]

11. Xing S, Bullen CK, Shroff NS, Shan L, Yang HC, Manucci JL, Bhat S, Zhang H, Margolick JB, Quinn TC, Margolis DM, Siliciano JD, Siliciano RF. Disulfiram reactivates latent HIV-1 in a Bcl-2-transduced primary $\mathrm{CD}^{+}{ }^{+} \mathrm{T}$ cell model without inducing global $\mathrm{T}$ cell activation. J Virol. 2011; 85:6060-6064. [PubMed: 21471244]

12. Matalon S, Rasmussen TA, Dinarello CA. Histone deacetylase inhibitors for purging HIV-1 from the latent reservoir. Mol Med. 2011; 17:466-472. [PubMed: 21424110]

13. Burnett JC, Lim KI, Calafi A, Rossi JJ, Schaffer DV, Arkin AP. Combinatorial latency reactivation for HIV-1 subtypes and variants. J Virol. 2010; 84:5958-5974. [PubMed: 20357084]

14. Huber K, Doyon G, Plaks J, Fyne E, Mellors JW, Sluis-Cremer N. Inhibitors of histone deacetylases: Correlation between isoform specificity and reactivation of HIV type 1 (HIV-1) from latently infected cells. J Biol Chem. 2011; 286:22211-22218. [PubMed: 21531716]

15. Brad Jones R, O’Connor R, Mueller S, Foley M, Szeto GL, Karel D, Lichterfeld M, Kovacs C, Ostrowski MA, Trocha A, Irvine DJ, Walker BD. Histone deacetylase inhibitors impair the elimination of HIV-infected cells by cytotoxic T-lymphocytes. PLOS Pathog. 2014; 10:e1004287. [PubMed: 25122219]

16. Sandler NG, Bosinger SE, Estes JD, Zhu RTR, Tharp GK, Boritz E, Levin D, Wijeyesinghe S, Nganou Makamdop K, del Prete GQ, Hill BJ, Timmer JK, Reiss E, Yarden G, Darko S, Contijoch E, Todd JP, Silvestri G, Nason M, Norgren RB Jr, Keele BF, Rao S, Langer JA, Lifson JD, Schreiber G, Douek DC. Type I interferon responses in rhesus macaques prevent SIV infection and slow disease progression. Nature. 2014; 511:601-605. [PubMed: 25043006]

17. Menne S, Tumas DB, Liu KH, Thampi L, AlDeghaither D, Baldwin BH, Bellezza CA, Cote PJ, Zheng J, Halcomb R, Fosdick A, Fletcher SP, Daffis S, Li L, Yue P, Wolfgang GHI, Tennant BC. Sustained efficacy and seroconversion with the Toll-like receptor 7 agonist GS-9620 in the Woodchuck model of chronic hepatitis B. J Hepatol. 2015; 62:1237-1245. [PubMed: 25559326] 
18. Lanford RE, Guerra B, Chavez D, Giavedoni L, Hodara VL, Brasky KM, Fosdick A, Frey CR, Zheng J, Wolfgang G, Halcomb RL, Tumas DB. GS-9620, an oral agonist of Toll-like receptor-7, induces prolonged suppression of hepatitis B virus in chronically infected chimpanzees. Gastroenterology. 2013; 144:1508-1517. 1517e1-10. [PubMed: 23415804]

19. Lopatin U, Wolfgang G, Tumas D, Frey CR, Ohmstede C, Hesselgesser J, Kearney B, Moorehead L, Mani Subramanian G, McHutchison JG. Safety, pharmacokinetics and pharmacodynamics of GS-9620, an oral Toll-like receptor 7 agonist. Antivir Ther. 2013; 18:409-418. [PubMed: 23416308]

20. Barouch DH, Liu J, Li H, Maxfield LF, Abbink P, Lynch DM, Iampietro MJ, SanMiguel A, Seaman MS, Ferrari G, Forthal DN, Ourmanov I, Hirsch VM, Carville A, Mansfield KG, Stablein D, Pau MG, Schuitemaker H, Sadoff JC, Billings EA, Rao M, Robb ML, Kim JH, Marovich MA, Goudsmit J, Michael NL. Vaccine protection against acquisition of neutralization-resistant SIV challenges in rhesus monkeys. Nature. 2012; 482:89-93. [PubMed: 22217938]

21. Letvin NL, Rao SS, Montefiori DC, Seaman MS, Sun Y, Lim SY, Yeh WW, Asmal M, Gelman RS, Shen L, Whitney JB, Seoighe C, Lacerda M, Keating S, Norris PJ, Hudgens MG, Gilbert PB, Buzby AP, Mach LV, Zhang J, Balachandran H, Shaw GM, Schmidt SD, Todd JP, Dodson A, Mascola JR, Nabel GJ. Immune and genetic correlates of vaccine protection against mucosal infection by SIV in monkeys. Sci Transl Med. 2011; 3:81ra36.

22. Whitney JB, Hill AL, Sanisetty S, Penaloza-MacMaster P, Liu J, Shetty M, Parenteau L, Cabral C, Shields J, Blackmore S, Smith JY, Brinkman AL, Peter LE, Mathew SI, Smith KM, Borducchi EN, Rosenbloom DIS, Lewis MG, Hattersley J, Li B, Hesselgesser J, Geleziunas R, Robb ML, Kim JH, Michael NL, Barouch DH. Rapid seeding of the viral reservoir prior to SIV viraemia in rhesus monkeys. Nature. 2014; 512:74-77. [PubMed: 25042999]

23. Whitney JB, Hraber PT, Luedemann C, Giorgi EE, Daniels MG, Bhattacharya T, Rao SS, Mascola JR, Nabel GJ, Korber BT, Letvin NL. Genital tract sequestration of SIV following acute infection. PLOS Pathog. 2011; 7:e1001293. [PubMed: 21379569]

24. Fosdick A, Zheng J, Pflanz S, Frey CR, Hesselgesser J, Halcomb RL, Wolfgang G, Tumas DB. Pharmacokinetic and pharmacodynamic properties of GS-9620, a novel Toll-like receptor 7 agonist, demonstrate interferon-stimulated gene induction without detectable serum interferon at low oral doses. J Pharmacol Exp Ther. 2014; 348:96-105. [PubMed: 24133297]

25. Foley JF, Yu CR, Solow R, Yacobucci M, Peden KWC, Farber JM. Roles for CXC chemokine ligands 10 and 11 in recruiting $\mathrm{CD}^{+}{ }^{+} \mathrm{T}$ cells to HIV-1-infected monocyte-derived macrophages, dendritic cells, and lymph nodes. J Immunol. 2005; 174:4892-4900. [PubMed: 15814716]

26. Dreyer K, Kallas EG, Planelles V, Montefiori D, McDermott MP, Hasan MS, Evans TG. Primary isolate neutralization by HIV type 1-infected patient sera in the era of highly active antiretroviral therapy. AIDS Res Hum Retroviruses. 1999; 15:1563-1571. [PubMed: 10580407]

27. Yant LJ, Friedrich TC, Johnson RC, May GE, Maness NJ, Enz AM, Lifson JD, O'Connor DH, Carrington M, Watkins DI. The high-frequency major histocompatibility complex class I allele Mamu- $B^{*} 17$ is associated with control of simian immunodeficiency virus SIVmac239 replication. J Virol. 2006; 80:5074-5077. [PubMed: 16641299]

28. Mothé BR, Weinfurter J, Wang C, Rehrauer W, Wilson N, Allen TM, Allison DB, Watkins DI. Expression of the major histocompatibility complex class I molecule Mamu-A*01 is associated with control of simian immunodeficiency virus $\operatorname{SIV}_{\text {mac }} 239$ replication. J Virol. 2003; 77:27362740. [PubMed: 12552014]

29. Loffredo JT, Maxwell J, Qi Y, Glidden CE, Borchardt GJ, Soma T, Bean AT, Beal DR, Wilson NA, Rehrauer WM, Lifson JD, Carrington M, Watkins DI. Mamu- $B^{*} 08$-positive macaques control simian immunodeficiency virus replication. J Virol. 2007; 81:8827-8832. [PubMed: 17537848]

30. Kuhrt D, Faith S, Hattemer A, Leone A, Sodora D, Picker L, Borghesi L, Cole KS. Naïve and memory B cells in the rhesus macaque can be differentiated by surface expression of CD27 and have differential responses to CD40 ligation. J Immunol Methods. 2011; 363:166-176. [PubMed: 20875419]

31. Webster RL, Johnson RP. Delineation of multiple subpopulations of natural killer cells in rhesus macaques. Immunology. 2005; 115:206-214. [PubMed: 15885126] 
32. Reeves RK, Gillis J, Wong FE, Yu Y, Connole M, Johnson RP. CD16- natural killer cells: Enrichment in mucosal and secondary lymphoid tissues and altered function during chronic SIV infection. Blood. 2010; 115:4439-4446. [PubMed: 20339088]

33. Pitcher CJ, Hagen SI, Walker JM, Lum R, Mitchell BL, Maino VC, Axthelm MK, Picker LJ. Development and homeostasis of T cell memory in rhesus macaque. J Immunol. 2002; 168:29-43. [PubMed: 11751943]

34. Whitney JB, Luedemann C, Hraber P, Rao SS, Mascola JR, Nabel GJ, Letvin NL. T-cell vaccination reduces simian immunodeficiency virus levels in semen. J Virol. 2009; 83:1084010843. [PubMed: 19640980]

35. Mattapallil JJ, Douek DC, Hill B, Nishimura Y, Martin M, Roederer M. Massive infection and loss of memory $\mathrm{CD}^{+}{ }^{+} \mathrm{T}$ cells in multiple tissues during acute SIV infection. Nature. 2005; 434:10931097. [PubMed: 15793563]

36. Giorgi EE, Funkhouser B, Athreya G, Perelson AS, Korber BT, Bhattacharya T. Estimating time since infection in early homogeneous HIV-1 samples using a Poisson model. BMC Bioinformatics. 2010; 11:532. [PubMed: 20973976]

37. Keele BF, Giorgi EE, Salazar-Gonzalez JF, Decker JM, Pham KT, Salazar MG, Sun C, Grayson T, Wang S, Li H, Wei X, Jiang C, Kirchherr JL, Gao F, Anderson JA, Ping L-H, Swanstrom R, Tomaras GD, Blattner WA, Goepfert PA, Michael Kilby J, Saag MS, Delwart EL, Busch MP, Cohen MS, Montefiori DC, Haynes BF, Gaschen B, Athreya GS, Lee HY, Wood N, Seoighe C, Perelson AS, Bhattacharya T, Korber BT, Hahn BH, Shaw GM. Identification and characterization of transmitted and early founder virus envelopes in primary HIV-1 infection. Proc Natl Acad Sci USA. 2008; 105:7552-7557. [PubMed: 18490657]

38. Rodriguez F, Oliver JL, Marin A, Medina JR. The general stochastic model of nucleotide substitution. J Theor Biol. 1990; 142:485-501. [PubMed: 2338834]

39. Yang Z. Maximum likelihood phylogenetic estimation from DNA sequences with variable rates over sites: Approximate methods. J Mol Evol. 1994; 39:306-314. [PubMed: 7932792]

40. Schmitz JE, Kuroda MJ, Santra S, Sasseville VG, Simon MA, Lifton MA, Racz P, Tenner-Racz K, Dalesandro M, Scallon BJ, Ghrayeb J, Forman MA, Montefiori DC, Rieber EP, Letvin NL, Reimann KA. Control of viremia in simian immunodeficiency virus infection by $\mathrm{CD}^{+}$ lymphocytes. Science. 1999; 283:857-860. [PubMed: 9933172]

41. Schmitz JE, Simon MA, Kuroda MJ, Lifton MA, Ollert MW, Vogel C-W, Racz P, Tenner-Racz K, Scallon BJ, Dalesandro M, Ghrayeb J, Peter Rieber E, Sasseville VG, Reimann KA. A nonhuman primate model for the selective elimination of $\mathrm{CD}^{+}$lymphocytes using a mouse-human chimeric monoclonal antibody. Am J Pathol. 1999; 154:1923-1932. [PubMed: 10362819]

42. Donaldson MM, Kao SF, Eslamizar L, Gee C, Koopman G, Lifton M, Schmitz JE, Sylwester AW, Wilson A, Hawkins N, Self SG, Roederer M, Foulds KE. Optimization and qualification of an 8color intracellular cytokine staining assay for quantifying $\mathrm{T}$ cell responses in rhesus macaques for pre-clinical vaccine studies. J Immunol Methods. 2012; 386:10-21. [PubMed: 22955212] 
A

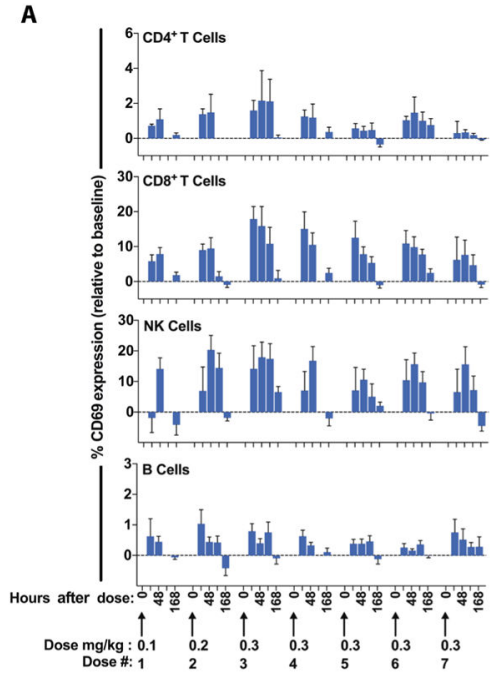

B

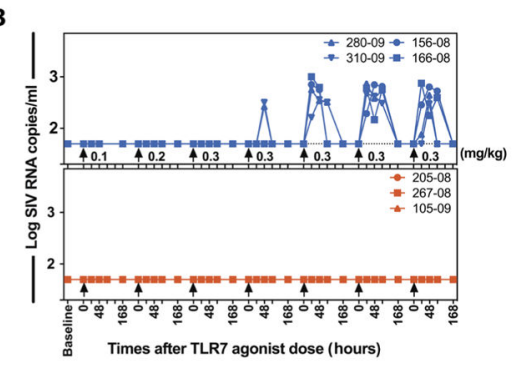

Fig. 1. Lymphocyte activation and transient plasma viremia in SIV-infected monkeys on ART after GS-986 treatment (study 1)

Macaques ( $n=4$; blue) were treated with escalating doses of GS-986 over the 14 weeks of the study. Dose concentrations were 0.1 and $0.2 \mathrm{mg} / \mathrm{kg}$, and then five consecutive doses of $0.3 \mathrm{mg} / \mathrm{kg}$ were given orally every other week. The control group received formulation vehicle only ( $n=6$, red). (A) Activation of lymphocyte subsets in the peripheral blood of rhesus macaques treated with escalating doses of GS-986 was monitored by flow cytometric detection of CD69. Expression of CD69 was measured in $\mathrm{CD}^{+}{ }^{+} \mathrm{T}$ cells, $\mathrm{CD}^{+} \mathrm{T}$ cells, NK cells, and B cells. CD69 expression was measured at pre-GS-986 dosing (0 hours) and then at 24, 48, 72, and 168 hours after GS-986 treatment. The absolute differences in percent CD69 expression by cells from time of treatment (baseline), for each of seven doses, are shown. Bar height indicates mean difference. Error bars indicate SEM. (B) Number of SIV RNA copies (expressed as $\log _{10}$ copies $/ \mathrm{ml}$ ) in plasma of SIV-infected rhesus macaques on ART after a single oral dose of TLR7 agonist every other week. 


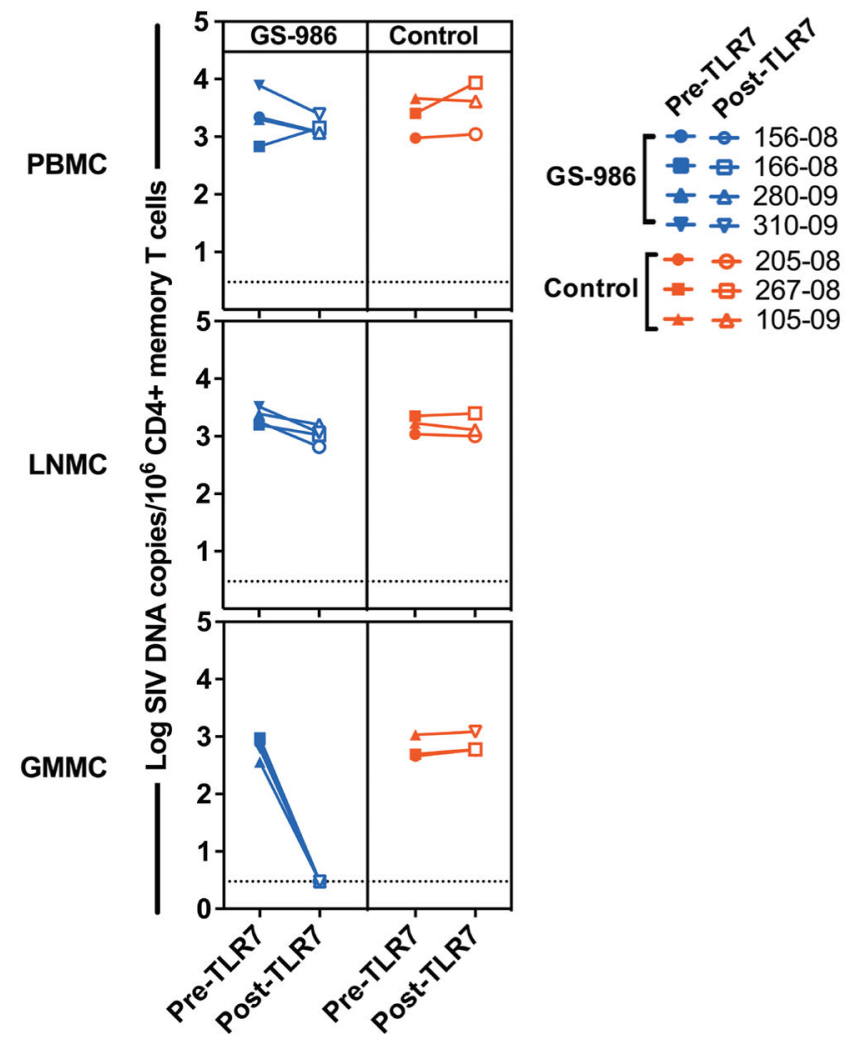

Fig. 2. Effect of TLR7 agonist on cell-associated viral DNA in $\mathrm{CD4}^{+} \mathrm{T}_{\text {memory }}$ cells from SIVinfected rhesus macaques on ART (study 1)

PBMCs, inguinal LNMCs, and GMMCs were collected from rhesus macaques before the administration of the TLR7 agonist GS-986 (pre-TLR7) and 1 week after the seventh dose of GS-986 (post-TLR7). Mononuclear cells were isolated from each tissue and sorted into four populations of $\mathrm{CD}^{+}{ }^{+} \mathrm{T}$ cells: naïve, central memory $(\mathrm{CM})$, transitional memory (TM), and effector memory (EM). Memory T cell subsets were then pooled. SIV DNA in the pooled memory $\mathrm{T}$ cell populations is expressed as $\log _{10}$ copies per $10^{6}$ cells. Threshold of detection, as indicated by the dotted line, is $<3$ copies per $10^{6}$ cells. 


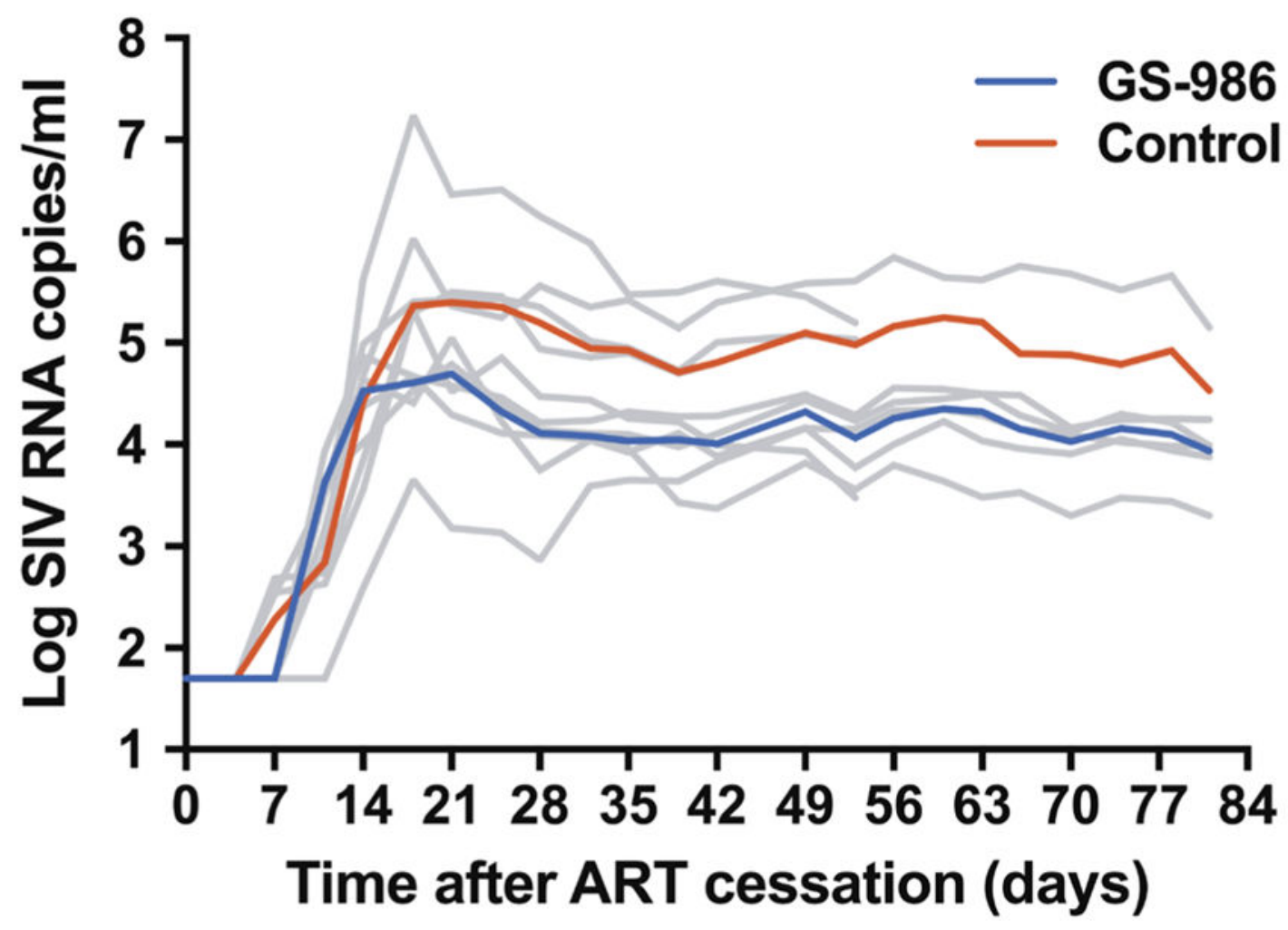

Fig. 3. The kinetics of SIV RNA rebound in the plasma of SIV-infected rhesus macaques after ART cessation (study 1)

$\log _{10}$ SIV RNA copies/ml in plasma was assessed in SIV-infected rhesus macaques for days 1 to 84 after ART cessation. Median $\log _{10}$ SIV RNA copies/ml for GS-986-treated (blue) and control vehicle-treated (red) animals is shown relative to the value on the day that ART was stopped (day 0). 
A

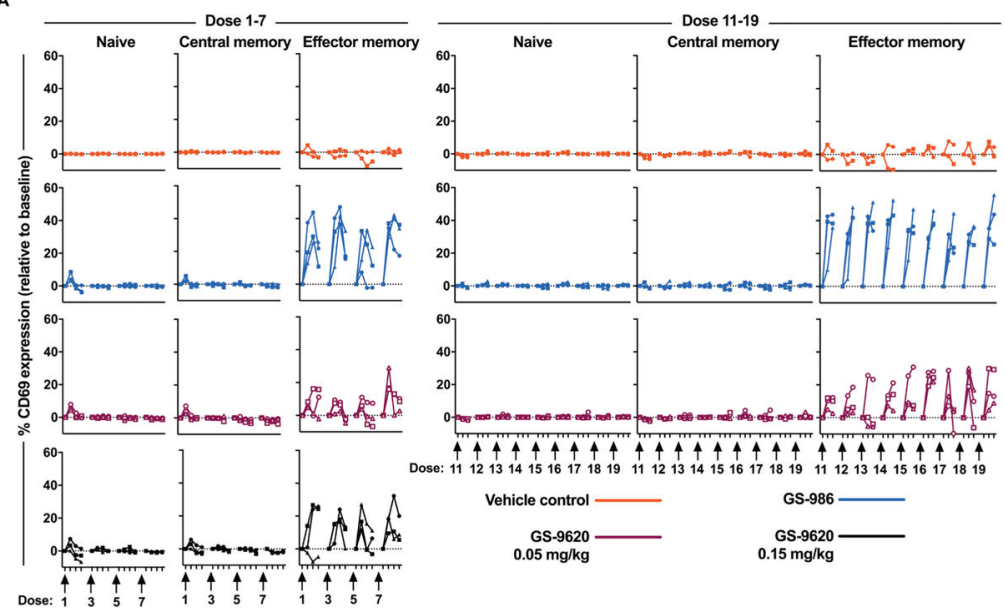

B
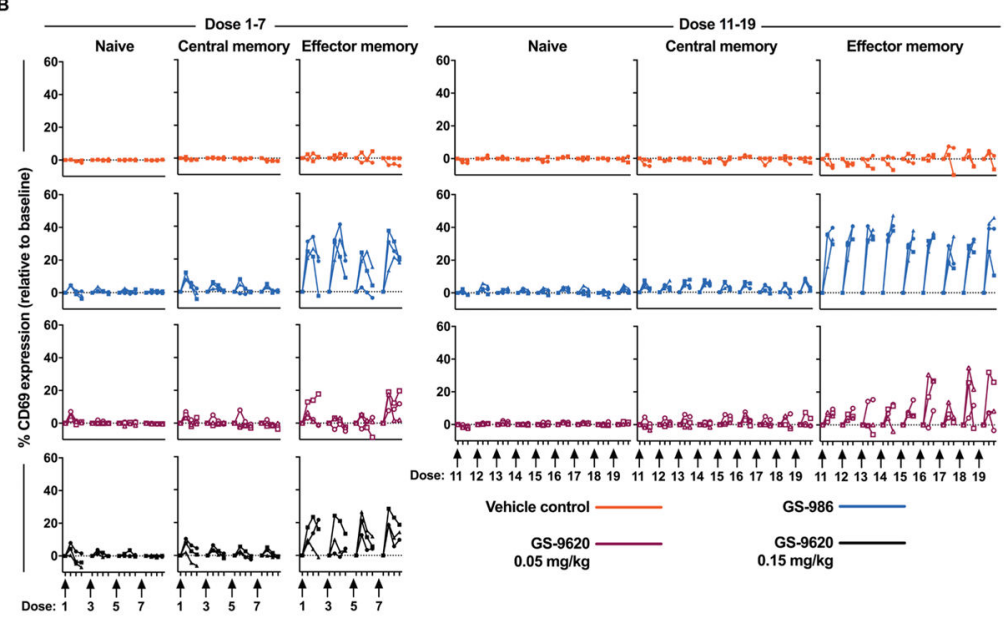

Fig. 4. Activation of effector memory $T$ cells by TLR agonists (study 2 )

Activation of naïve $\left(\mathrm{CD} 95^{-} \mathrm{CD} 28^{+}\right)$, central memory $\left(\mathrm{CD} 95^{+} \mathrm{CD} 28^{+}\right)$, and effector memory $\left(\mathrm{CD}^{+} 5^{+} \mathrm{CD} 28^{-}\right) \mathrm{T}$ cells for $\mathrm{CD}^{+}(\mathbf{A})$ and $\mathrm{CD}^{+}(\mathbf{B}) \mathrm{T}$ cell populations in the peripheral blood of SIV-infected rhesus macaques on ART is shown. Rhesus macaques were treated with vehicle (red), GS-986 (0.1 mg/kg; blue), GS-9620 (0.05 mg/kg; purple), or GS-9620 $(0.15 \mathrm{mg} / \mathrm{kg}$; black). T cell activation was measured by flow cytometric detection of CD69. CD69 expression within each $\mathrm{T}$ cell subset was measured at the time of the first dose (baseline) and at 24, 48, and 72 hours (doses 1 to 7 only) after the first dose (time points indicated by black arrows on $x$ axis). Data for doses 1, 3, 5, and 7 are shown on the left, and data for doses 11 to 19 are shown on the right. Changes in CD69 expression are shown as absolute difference in percent from baseline for naïve, central memory, and effector memory $\mathrm{T}$ cell subsets. 


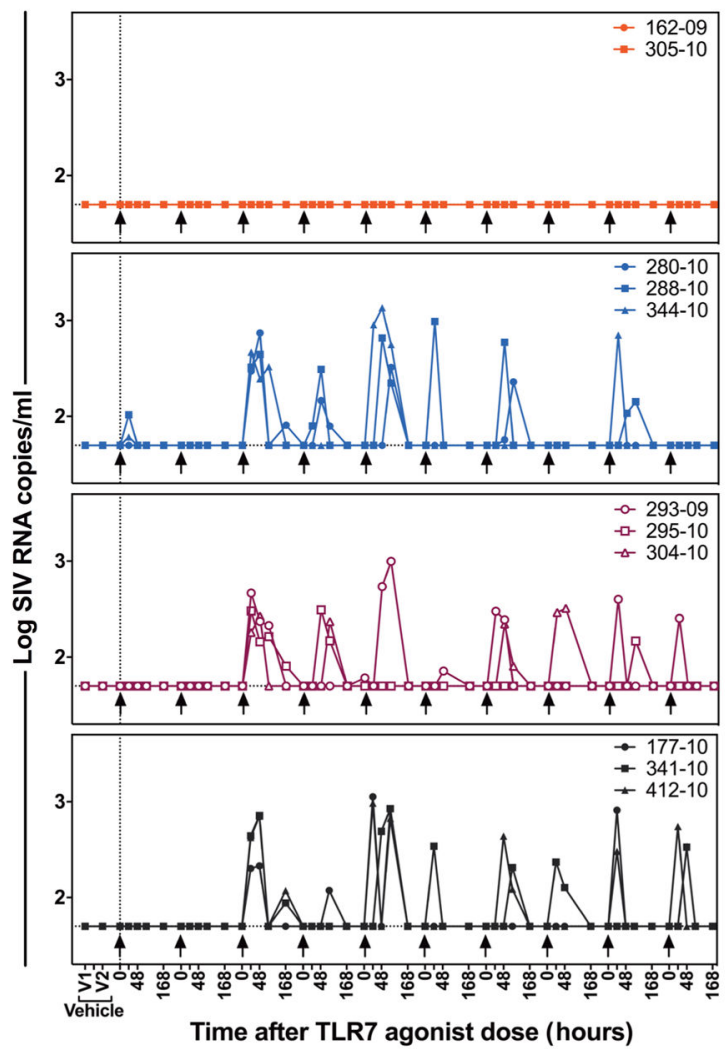

Fig. 5. Transient plasma viremia induced by TLR7 agonist dosing of SIV-infected macaques on ART (study 2)

SIV-infected rhesus macaques on ART were treated with vehicle ( $n=2$; red), GS-986 (0.1 $\mathrm{mg} / \mathrm{kg} ; n=3$; blue), GS-9620 (0.05 mg/kg; $n=3$; purple), or GS-9620 (0.15 mg/kg; $n=3$; black) over the 23 weeks of the study. Plasma viral RNA in vehicle-treated or TLR7 agonist-dosed animals is shown. Black arrows indicate the timing of each TLR7 agonist dose. The horizontal dotted line represents the limit of detection of plasma viremia, which was 50 SIV RNA copies/ml. 
A

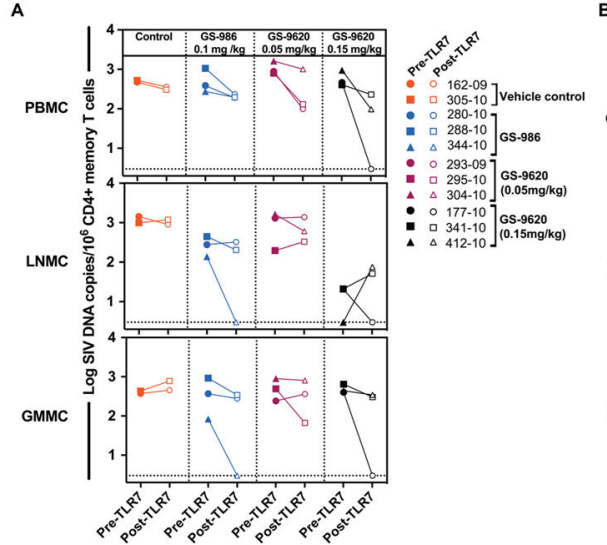

c

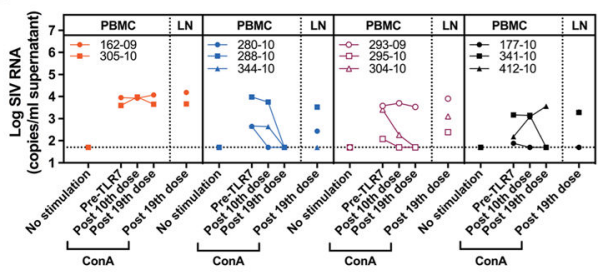

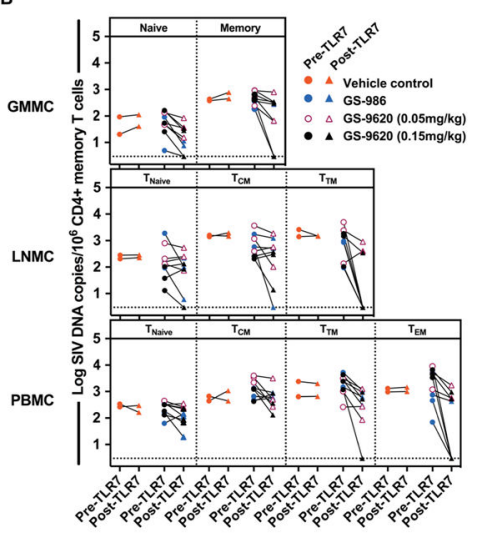

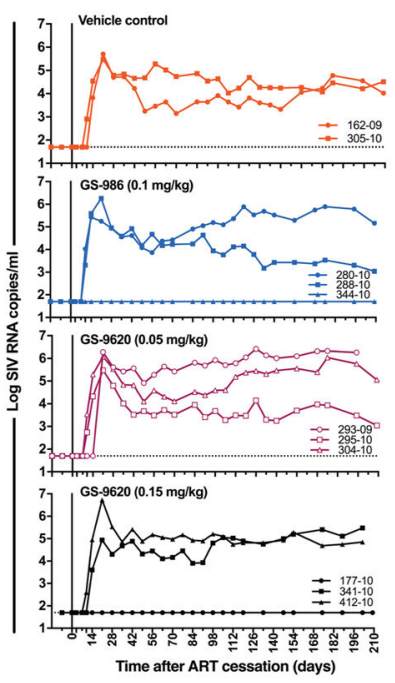

Fig. 6. Changes in cell-associated viral DNA in mononuclear cells isolated from tissues of SIVinfected macaques treated with TLR7 agonists (study 2)

(A) Mononuclear cells were isolated from tissues of animals treated with either vehicle (red), GS-986 (0.1 mg/kg; blue), GS-9620 [0.05 mg/kg (purple) or $0.15 \mathrm{mg} / \mathrm{kg}$ (black)]. Mononuclear cells were sorted into four populations of $\mathrm{CD}^{+} \mathrm{T}$ cells: naïve, central memory, transitional memory, and effector memory, and then memory $\mathrm{T}$ cell subsets for GMMCs were pooled to increase sensitivity for SIV DNA analysis. SIV DNA is expressed as $\log _{10}$ copies per $10^{6} \mathrm{CD} 4^{+}$memory $\mathrm{T}$ cells at the time of administration of the TLR7 agonist (pre-TLR7) and a week before stopping ART (post-TLR7). (B) SIV DNA ( $\log _{10}$ copies per $10^{6}$ cells) in each subpopulation of $\mathrm{CD}^{+} \mathrm{T}$ cells from TLR7-treated rhesus macaques pre- and post-TLR7 agonist treatment. The threshold of detection, as indicated by the horizontal dotted line, is $<3$ copies per $10^{6} \mathrm{CD}^{+} \mathrm{T}$ cells. Changes in SIV DNA between pre- and post-TLR7 treatment were compared using a Wilcoxon matched paired test. (C) Results of an ex vivo mitogen-stimulated virus production assay. PBMCs or LNMCs (post-19th dose only) were isolated from macaques before the administration of the first dose of TLR7 agonist (pre-TLR7) and then after the 10th and 19th doses of the TLR7 agonist (post-TLR7). Cells were grown in basal culture medium supplemented with $10 \mathrm{mM}$ raltegravir, with or without concanavalin A (ConA; $5 \mu \mathrm{g} / \mathrm{ml})$ for 6 days. The number of SIV 
RNA copies/ml of supernatant on day 6 is shown. (D) SIV plasma RNA rebound kinetics in SIV-infected macaques after cessation of ART. The viral rebound kinetics after stopping ART were assessed in groups of animals treated with either vehicle control $(n=2$; red), GS-986 (0.1 mg/kg; $n=3$; blue), GS-9620 (0.05 mg/kg; $n=3$; purple), or GS-9620 (0.15 $\mathrm{mg} / \mathrm{kg} ; n=3$; black). Log plasma virus RNA was assessed between days 1 and 210 after ART cessation. 
A
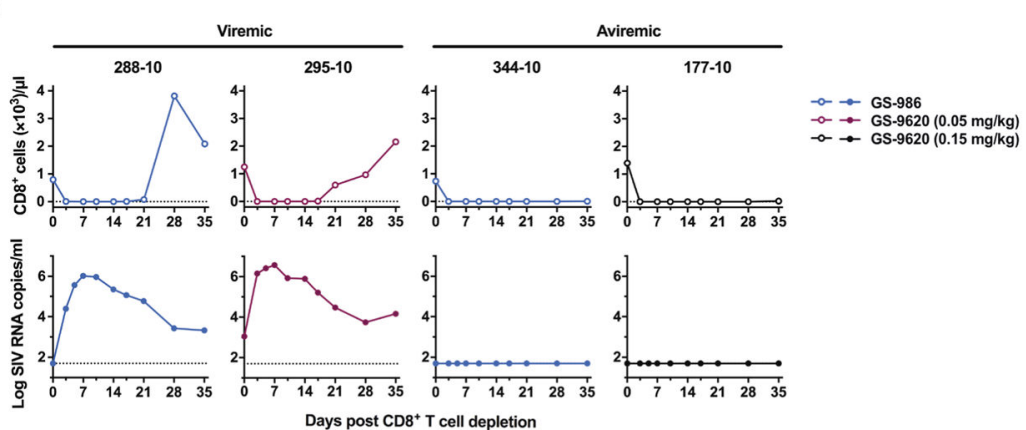

B

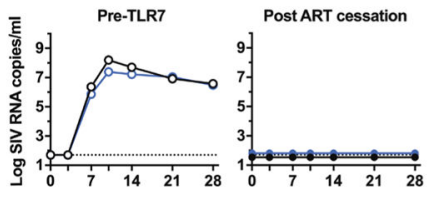

Fig. 7. Number of $\mathrm{CD8}^{+}$lymphocytes and plasma SIV RNA kinetics after in vivo $\mathrm{CD8}^{+}$cell depletion

(A) $\mathrm{CD}^{+}$lymphocytes were depleted in vivo by infusion of monoclonal antibody

MT807R1, and numbers of $\mathrm{CD}^{+}$cells per microliter of whole blood were monitored by flow cytometry for four macaques (two aviremic and two viremic). Log plasma virus RNA was assessed between days 0 and 35 after $\mathrm{CD}^{+}$cell depletion. (B) Four SIV-naïve rhesus macaques served as recipients for adoptive transfer of cells from two donor rhesus macaques in remission. Left: In the first transfer, about 50 million frozen PBMCs and LNMCs from donor animals 177-10 and 344-10, isolated after the initiation of ART but before TLR7 agonist treatment, were used for adoptive transfer. For each donor rhesus macaque (177-10, black; 344-10, blue), PBMCs and LNMCs were thawed, combined, and then infused into two naïve rhesus macaques. Right: In the second transfer, about 120 million fresh PBMCs and LNMCs from each donor were isolated at 448 days after cessation of ART. PBMCs and LNMCs were combined and then infused into two additional naïve rhesus macaques. Log plasma virus RNA was assessed between days 0 and 28 after adoptive transfer. 